\title{
Hydration and synergistic features of nanosilica-blended high alkaline white cement pastes composites
}

\author{
M. A. Abdelzaher ${ }^{1}$ (D) Nabila Shehata ${ }^{1}$
}

Received: 28 November 2021 / Accepted: 26 January 2022 / Published online: 14 February 2022

(c) The Author(s) 2022

\begin{abstract}
Nanosilica (NS) behavior on hydration and synergistic characteristics of highly alkaline (HA) white cement pastes composites containing 5-25 mass \% of NS (as substitution) was studied. The hydration kinetics behavior from 1 to 100 days was examined for all the blends e.g.: whiteness reflection $\left(R_{\mathrm{y}}\right)$, setting, compressive mechanical strength (CS), bulk density (BD), combined water content $\left(W_{\mathrm{n}}\right)$, total porosity (TP), and free lime (FL) have all been checked. The substitution of 5 wt.\% NS has improved the compression mechanical strength and physico-chemical features of HA-white cement pastes composite, especially the compressive mechanical strength, free lime content and bulk density. X-ray Diffraction (XRD) and Scanning Electron Microscopy (SEM) techniques have been implemented to investigate the microstructure and features of NS pastes composites. NS (5\%) improved the synergistic and hydration properties of the evaluated composite materials. NS has a substantial impact on the performance of HA-white cement composite pastes, reducing whiteness reflection $\left(R_{\mathrm{y}}\right)$, total porosity and setting times while enhancing mechanical strength, bulk density and gel-to-space ratio. SEM showed a thicker fiber microstructure and more calcium silicate hydrate products lead to a sharp decrease in porosity of all NS composites so it enhances the mechanical and physical properties, as well as the original morphology of calcium mono-carboaluminate hydrate. Highly recommended NS cement composite containing 95 percent +5 percent NS has better performance and synergy than ordinary white cement. It showed a compact, high-density microstructure consisting of a large proportion of the microcrystalline fibrous group leading to reduced porosity of the blend.
\end{abstract}

Keywords Nanosilica (NS) $\cdot$ Gel-to-space ratio $\cdot$ Highly alkaline white cement $\cdot$ Combined water content $\cdot$ XRD and SEM microstructure

\section{Introduction}

There is a growing dependence on the building and construction materials industry on the reused/recycled supplemental cementitious materials (SCMs), solid wastes and industrial by-products for the production of eco-cements which are recently preferred in green and sustainable synthesis of construction/building materials (Antwi-Afari et al. 2021; Tayeh et al. 2020; El-Kattan et al. 2020; Juenger et al. 2019). Utilization of by-products generated from industrial plants, such as ground blast furnace slag (GGBS), ashes, silica fume, ceramic waste and many other solid wastes,

M. A. Abdelzaher

M.abuelseoud@psas.bsu.edu.eg

1 Environmental Science and Industrial Development Department, Faculty of Postgraduate Studies for Advanced Sciences, Beni-Suef University, Beni Suef 62511, Egypt is possibly applicable a for minimizing the clinker/cement ratio content and the production cost subsequently. The focus toward minimizing this ratio is attributed to that the clinker is the densest component of carbon dioxide in the cement process. For example, blending pastes comprising ordinary Portland cement (OPC) with 10-30 wt\% GGBS or 10-20 $\mathrm{wt} \%$ ashes commercial present in the market according to the standards of GB-175, 2015, EN 197-1, 2011 and ASTM C-989. Despite, owing to accelerate the consumption rates by the building materials industry and other consuming sectors, in addition to the restricted supply, it is projected that appropriate SCMs, it will become unusable in the near future(Elkhouly et al. 2021). Moreover, the strict adoption of climate change agreements worldwide in COP2021, has jeopardized the sustainability of many cement factories, hence reduction in the produced amount of $\mathrm{CO}_{2}$. Consequently, an increasing dependence on the import of SCMs has been reported in several developed countries. Alternative 
SCMs, which have been widely distributed all over the world, have never been a favorite.

Recently, research and commercial interest has been focused on limestone-calcined clay cement (LC3) and green cement owning to that developing of a high replacement ratio up to $40.0 \mathrm{wt} \%$, it can achieve results equal to or even better than ordinary cement and concrete mixture when designed with a carefully approved pozzolans substitution with the availability of the main precursors (i.e., clay, limestone and sand). Supplementary Cement Material (SCM) is classified into two types: natural SCM (zeolite, white sand, and volcanic tuff) and synthetic SCM (metakaolin, silica fume and fly ash, and slag) (Avet et al. 2019; Pillai et al. 2019; Nguyen et al. 2020a, 2020b; Hou et al. 2021). They may significantly improve the mechanical hydraulic properties, due to their pozzolanic interaction (Sharma et al. 2021; Abdelzaher et al. 2018). Among them are those finer than cement, such as fly ash, which is very effective not only because of its tremendous surface area, which makes it highly activated, but also because of its precise size, which allows it to fill in the spaces between cementing materials, resulting in an increase in bulk density and a reduction in total porosity (Wilińska and Pacewska 2014; Lin et al. 2014; Tantawy et al. 2012; Velázquez et al. 2016; Balboul et al. 2019). The implementation of pozzolanic materials in cement/concrete is economic due to the partial substitution of a large percentage of Portland cement with low-cost industrial by-products, resulting in lowering of the greenhouse gases generated during cement production and also they enhance the durability and workability of the final product. Moreover, increasingly blending of pozzolan with OPC creates added value by converting huge quantities of useless industrial solid wastes into sustainable building materials. The features of the developed blended cement are mostly dependent on the selected filler microstructure, which are, the distribution, type, matrix, pores sizing and reactions products. The merits of adding pozzolans are the high compressive mechanical strength, great workability and durability mostly attributable to pozzolanic reactions as calcium hydroxide is totally reacted to produce extra C-A-H and $\mathrm{C}-\mathrm{S}-\mathrm{H}$ reaction products. Additionally, the products of Pozzolanic reaction fill the open pores and rearrange the particles which reduce in the total porosity of blends. However, By changing the $\mathrm{pH}$ of the cement, the pozzolanic reaction can minimize the risk of expanding alkaline silica reactions between the cement and the aggregate. However, increasing alumina concentrations and lowering the solution alkalinity decrease or inhibit the dissolution of the aggregate aluminosilicates (Thomas 2011; Abdelzaher 2021; Shi et al. 2018).

The addition of white sand as SCM to cement/clinker completes the fine structure in the cement granulometric curve without increasing water consistency, plugs all capillary pores and enhances cement packing. As a result, numerous researches shown that adding white sand to cement reduces water demand (Tantawy et al. 2013; AlJabri et al. 2013), setting times, and porosity (Abbas et al. 2021), while increasing combined water content (Abbas et al. 2021; Janotka et al. 2010) and compressive mechanical strength up to $15 \%$ of cement composites (Tantawy et al. 2013; Damidot et al. 2011). White sand enhances the rate of hydration at an early age, which causes high early compression results (Alhozaimy et al. 2012), and interacts, with phases of ferrite and aluminate in cement to develop monocarbo-aluminate (Guettala and Mezghiche 2011; Zhang et al. 2006). The inclusion of white sand can lead to shape some calcium carbo-silicate hydrate and a reduction of the potential cement material (thinning effect), leading to a subsequent gain of strength (Guettala and Mezghiche 2011; Zhang et al. 2006). The most serious durability issues seen with Portland white sand cements are susceptibility to extremely harsh environments. The most serious durability issues identified with Portland white sand cements in extremely hostile settings are prone to sulfate attack (particularly taumasite production) and chloride diffusion, depending on the amount supplied (Damidot et al. 2011). In contrast, inclusion of white sand marginally raises demand for water and overall total porosity of Portland cement composites while decreasing setting durations and bulk density (Abdullah and Alhozaimy 2013; Alhozaimy et al. 2013). Calculations of the specific volume of solids as a function of the white sand addition show that the space filling capacity of the paste is optimal if the white sand concentration is adjusted to maximize ettringite content.

The influence of nano-silica on the hydration of gray Portland cement was well studied worldwide. In addition, there are little works studied the hydration characteristics of white Portland cement. In contrast, there is a lack of knowledge dealing with the role of nano-silica on the hydration of high alkaline content white Portland cement. Hence, the aim of this study is to discuss the influence of nano-silica on the physico-mechanical and microstructure features of HA-white cement composites.

\section{Experimental assays}

\section{Materials resources}

HA-White cement (WC) [CEM I $52.5 \mathrm{~N}$ ], and nano-silica (NS) constituted the starting raw materials used in this lab study. The HA-WC purchased from Aalborg Portland cement Co., Aalborg plant, (Aalborg, CPH). Nano-silica was purchased from Sigma Aldresish Co., Egypt. Specific surface area of nanosilica was $6777 \mathrm{~cm}^{2} \cdot \mathrm{g}^{-1}$. Figures 1,2 show SEM and TEM microstructure of nano-silica and prove that NS is in nano-scale range from 56.81 to $97.44 \mathrm{~nm}$. The 


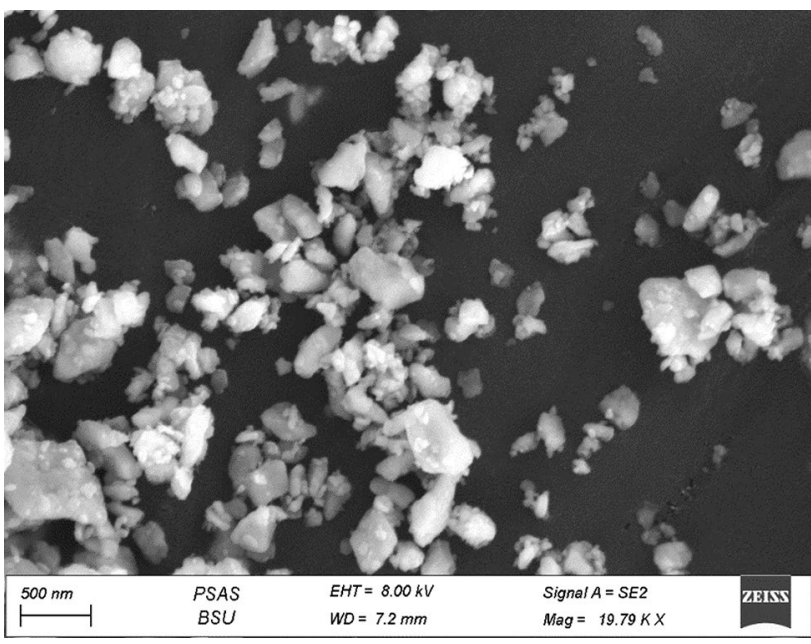

Fig. 1 SEM image of NS

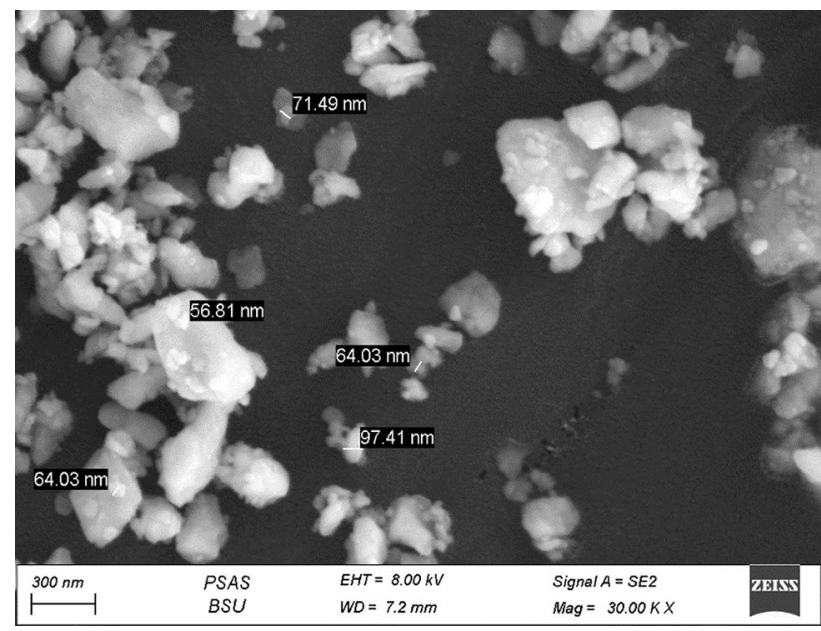

Fig. 2 TEM image of $\mid \mathrm{NS}$
$\mathrm{X}$-ray fluorescence (XRF) results show complete chemical compositions of both WC, and NS shown in Table 1.

\section{Preparation of cement paste composites, Testing procedures and Instruments}

Overall, HA-WC was substituted by 5, 10, 15, 20, and 25\% of NS, as shown in Table 2. The water/cement ratio was varied based on the weight percentage of NS mixed cement pastes. Composites pastes were intermixed in a high-speed (rpm) rotary mixer to inhibit NS coagulation; first, HA-WC was added to the mixer at low rpm for $1 \mathrm{~min}$, then at high rpm for $2 \mathrm{~min}$, and last, at $400 \mathrm{rpm}$, NS was entered to the homo-mixer for $90 \mathrm{~s}$. The patches were molded into $(2.5 \mathrm{~cm} * 2.5 \mathrm{~cm} * 2.5 \mathrm{~cm})$ steel molds, two layers of paste were manually pressed, and then fixed in $99.1 \%$, relative humidity $(\mathrm{RH})$ at ambient temperature. After one day, the specimens were de-molded and promptly cured in tap flow water at $100 \%$ RH until compressive strength testing periods of 3, 7, 28, and 100 days of hydration were completed. Curing conditions were set in accordance with (ASTM C150-07. 2007), which demonstrated the beneficial effect of high RH on the performance of NS-white cement pastes composites. Whiteness reflection $\left(R_{\mathrm{y}}\right)$ was measured using the "Elerpho" equipment in accordance with DIN 5033 specifications (NORM, Din. 1992). Setting times of NS mixes were determined using the Vicate equipment and ASTM C191 (ASTM 2013). Combined water content was measured by weighing $2 \mathrm{gm}$ (W1) of saturated samples at different curing ages, and then gradually ignited up to $1000{ }^{\circ} \mathrm{C}$ for $1 \mathrm{~h}$, then samples cooled down (W2). The following equation mainly used to determine $\mathrm{Wt}$ (American Society for Testing and Materials 1999):

Combined water content $(\mathrm{Wt}), \%=\frac{\mathrm{W} 1-\mathrm{W} 2}{\mathrm{~W} 2} * 100$
Table 1 Chemical composition of HA-white cement and Nanosilica

Table 2 The composition of NS-white cement pastes mixes

\begin{tabular}{llllllllllll}
\hline Oxide (\%) & $\mathrm{SiO}_{2}$ & $\mathrm{Al}_{2} \mathrm{O}_{3}$ & $\mathrm{CaO}$ & $\mathrm{Fe}_{2} \mathrm{O}_{3}$ & $\mathrm{MgO}$ & $\mathrm{SO}_{3}$ & $\mathrm{Na}_{2} \mathrm{O}$ & $\mathrm{K}_{2} \mathrm{O}$ & $\mathrm{Cl}^{-}$ & LOI & Total \\
\hline HA-WC & 21.76 & 2.65 & 67.77 & 0.11 & 0.23 & 3.05 & 0.66 & 0.38 & 0.09 & 3.15 & 99.850 \\
NS & 97.44 & 1.26 & 0.20 & 0.04 & 0.01 & 0.01 & 0.002 & 0.001 & 0.004 & 0.78 & 99.747 \\
\hline
\end{tabular}

\begin{tabular}{lllll}
\hline Mix title & \multicolumn{2}{l}{ Mix composition } & & \\
\cline { 2 - 5 } & $\begin{array}{l}\text { HA-WC by weight } \\
(\%)\end{array}$ & NS by weight $(\%)$ & Total mix batch $(\%)$ & Curing water \\
\hline M0 & 100.00 & 0.00 & 100.00 & Tab water \\
M-S5 & 95.00 & 5.00 & & \\
M-S10 & 90.00 & 10.00 & & \\
M-S15 & 85.00 & 15.00 & & \\
M-S20 & 80.00 & 20.00 & & \\
M-S25 & 75.00 & 25.00 & & \\
\hline
\end{tabular}


The hydration kinetics of NS cements were stopped by soaking the specimen in an (acetone 50\%: methanol 50\%) mixture for $24 \mathrm{hs}$, then drying at $70{ }^{\circ} \mathrm{C}$ oven for $2 \mathrm{~h}$, and a portion of the dried sample was retained for examination using SEM and XRD techniques. Compressive mechanical strength (CS) was oriented to three-hardened white cement specimen complies with ASTM C190 designations (ASTM C109, C109M 2016) employing 5 tons by (Toni Machine test) at compression rate of $25 \mathrm{~kg}$. $\mathrm{min}^{-1}$. Prior to determining the compressive mechanical strength (CS), bulk density (BD) and total porosity (TP) were examined as explain elsewhere (American Society for Testing and Materials 1999). We, has been determined by determining the bulk density (BD), combined water content $(\mathrm{Wt})$, and the evolved water $(\mathrm{We})$ of hardened NS cement pastes using Eq. (2) (Kurda et al. 2019).

$\hat{\mathrm{We}}=\frac{0.99 \mathrm{We} \cdot \mathrm{BD}}{(1+\mathrm{Wt})}$

The free lime content (F.CaO) of hardened NS cement pastes was measured analytically by inserting $0.5 \mathrm{gm}$ of dried crushed cubes powder in $0.05 \mathrm{~L}$. ethylene glycol, boiling to $70{ }^{\circ} \mathrm{C}$ for $30 \mathrm{~min}$ in a swirling water path, and titrated with HCL (0.1 N), using Eq. (3) (Ali et al. 2008).
F. $\mathrm{CaO} \%=0.56 \times \operatorname{VofHCL}$

Figure 3 shows the schematic diagram for experimental program. The microstructures using SEM technique generated with Gemini (Sigma 500 VP, 2020 version). On the other hand, the present oxides that ingested NS and WC were quantified using XRF performed with a comprehensive instrument Panalytical (ARL 9900). Another part of dried sample was milled to pass from (25 $\mathrm{mm}$ sieve) to determine phases of hydration using X-ray diffraction (XRD), which carried out using Philips (PW3050/60) diffractometer using a scanning range from 5 to $502 \varnothing$, with a scanning speed of $1 \mathrm{~s} / \mathrm{step}$ and resolution of $0.05 \%$ step. Whiteness reflection (Ry) was obtained using Elerpho instrument (PCE-WNM 100 ), measuring range: $0-120$, resolution $\approx 0.01$, repeat accuracy $<0.5$ and $45 / 0$ measuring geometry.

\section{Results and discussion}

\section{Whiteness reflection (Ry)}

NS had a very pale white color, so its whiteness degree on the Elerpho instrument was very low, particularly the

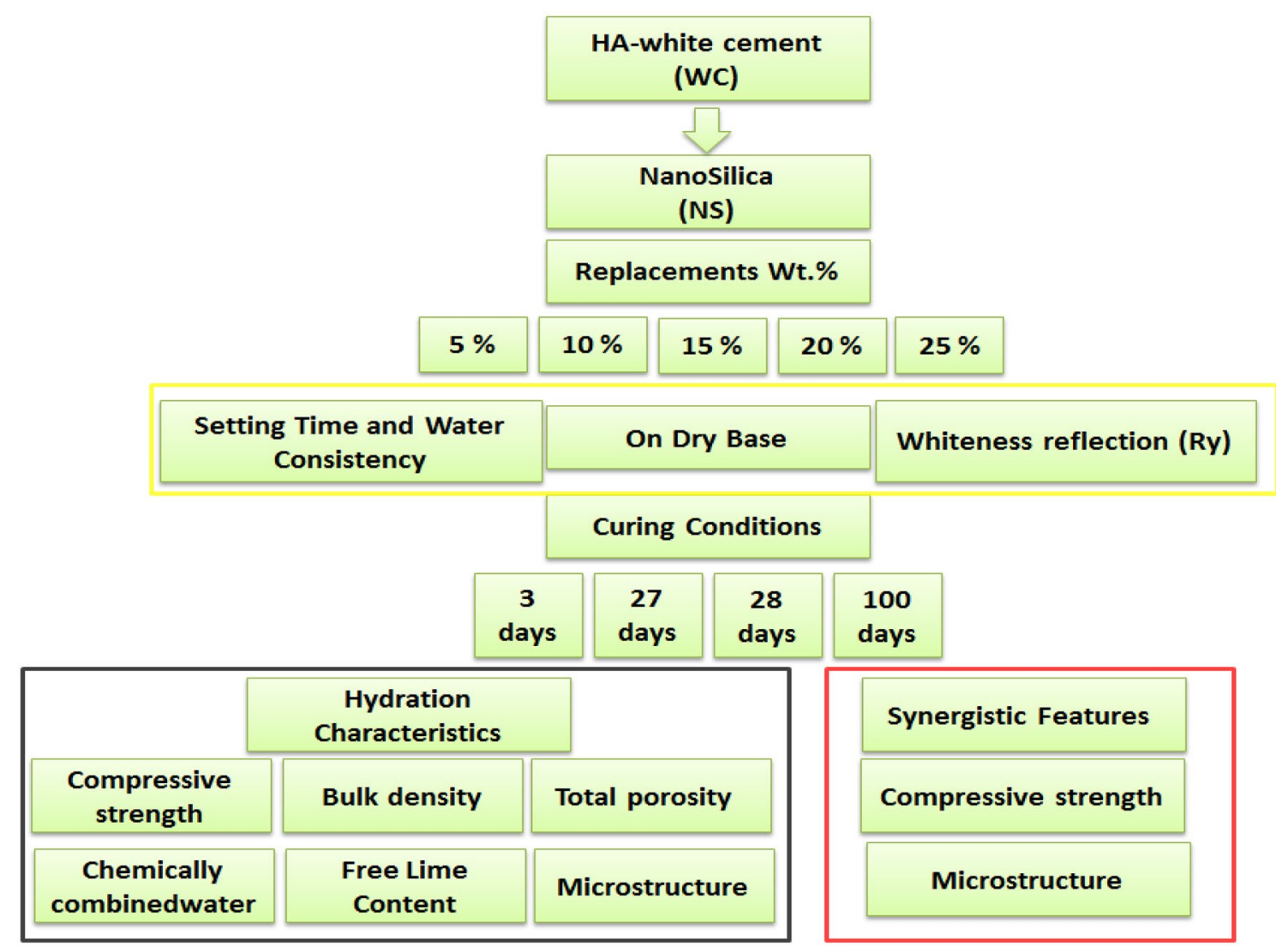

Fig. 3 Schematic diagram for experimental program 
Table 3 Whiteness reflection $\left(R_{\mathrm{y}}\right)$ of the mixes

\begin{tabular}{lllllll}
\hline Mix title & \multicolumn{5}{l}{ Whiteness reflection (Ry) } \\
\cline { 2 - 6 } & $R_{\mathrm{x}}$ & $R_{\mathrm{y}}$ & $R_{\mathrm{z}}$ & HL & Ha & $\mathrm{Hb}$ \\
\hline M0 & 84.10 & 84.00 & 80.76 & 91.65 & -1.05 & 2.47 \\
NS & 81.10 & 81.40 & 76.00 & 90.22 & -2.53 & 4.19 \\
M-S5 & 83.91 & 83.80 & 80.23 & 91.54 & -1.16 & 2.73 \\
M-S10 & 82.60 & 82.30 & 78.77 & 90.72 & -0.86 & 2.72 \\
M-S15 & 82.35 & 82.00 & 77.10 & 90.55 & -1.32 & 3.79 \\
M-S20 & 79.92 & 78.80 & 73.70 & 88.77 & -0.22 & 4.02 \\
M-S25 & 77.68 & 77.50 & 72.29 & 88.03 & -1.75 & 4.14 \\
\hline
\end{tabular}

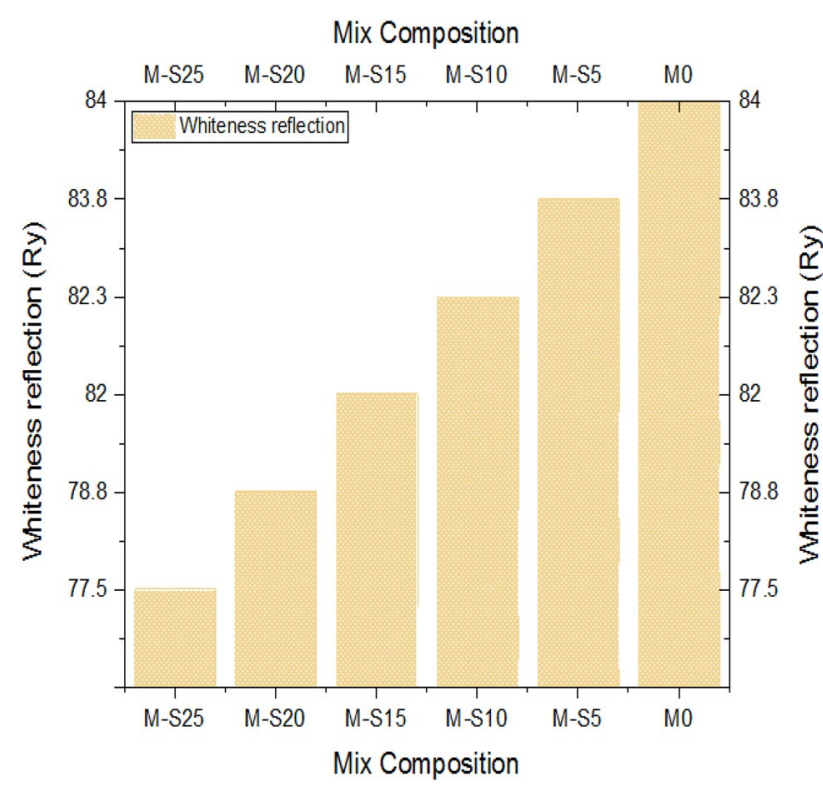

Fig. 4 Whiteness reflection (Ry) of white cement with and/or without NS (dry base)

third axis ( $\mathrm{Rz}$ axis), that administers the green whiteness reflection, e.g., $\mathrm{Ha}=-2.53$ vs. $\mathrm{Ha}=-1.05$ for $\mathrm{WC}$, which emphasizes the reduction at the mixes whiteness reflection degree $\left(R_{\mathrm{y}}\right)$, as shown in Table 3. WC whiteness reflection $\left(\mathrm{R}_{\mathrm{y}}\right)$ with/without nano-silica (NS) graphically reported in Fig. 4. It clear that, the increment of NS wt.\%, leads to the $\left(R_{\mathrm{y}}\right)$ values decrement. It was followed by the order: Ry-M0 > Ry-M-S5 > Ry-M-S10 > Ry-M-S $15>$ Ry-MS20 > Ry-M-S25. The Ry degree changes from $84.0 \%$ of (M0) as WC without NS to $77.50 \%$ of (M-S25) with the largest substitution of NS substitution ratio. Moreover, the $\left(R_{\mathrm{y}}\right)$ of (M-S5) presented the greatest result after M0 by $83.80 \%$. This owes to the NS powder $\left(R_{\mathrm{y}}\right)$ equal to $81.40 \%$, that impacts marginally on whiteness of WC on a dry base.

\section{Setting time and water consistency}

Setting times and water consistency (W/C) of the WC composite pastes including NS are tabulated in Table 4 and
Table 4 Setting time, water consistency and flowability of the mixes

\begin{tabular}{|c|c|c|c|c|}
\hline \multirow[t]{2}{*}{ Mix title } & \multicolumn{2}{|c|}{ Setting time (min) } & \multirow{2}{*}{$\begin{array}{l}\text { Water consist- } \\
\text { ency }\end{array}$} & \multirow{2}{*}{$\begin{array}{l}\text { Flowa- } \\
\text { bility } \\
(\mathrm{mm})\end{array}$} \\
\hline & Initial & Initial & & \\
\hline M0 & 120 & 215 & 0.37 & 139 \\
\hline M-S5 & 140 & 270 & 0.48 & 167 \\
\hline M-S10 & 155 & 295 & 0.52 & 163 \\
\hline M-S15 & 170 & 315 & 0.55 & 158 \\
\hline M-S20 & 210 & 325 & 0.56 & 142 \\
\hline M-S25 & 220 & 345 & 0.61 & 141 \\
\hline
\end{tabular}

Fig. 5, illustrates both initial and final setting times of WC and NS composites white cement pastes as function of time. It was noted that the white cement composite pastes substituting 5 and 10 mass \% NS need a lower water demand, 0.45 and $0.48 \%$, respectively. Due to tremendous active area of the NS, this cement mix has the quickest setting periods when compared to other WC composite cement blends containing the NS (Zhang et al. 2012). The released $\mathrm{Ca}^{2+}$ and $\mathrm{OH}^{-}$accessible from the hydration kinetics of the hydration phases with the curing tap water interact with the nanosilica (NS), resulting in an excess of calcium aluminate hydrate (C-A-H), calcium silicate hydrate $(\mathrm{C}-\mathrm{S}-\mathrm{H})$, and gel calcium aluminosilicate (C-ASH) hydrated. The NS serves as an active crystal location for the formation of further $\mathrm{CSH}$ stages later on.

Therefore, the setting time is reduced unlike the highest replacement blend M-S25 which has the higher water demand and recorded the highest setting time results. In addition, the water consistency increment due to the high dispersion of the NS, may prove that the increment active area energy requires more water consistency (Cao et al. 2015; Hou et al. 2013) because of the decrement in the fresh prepared pastes flowability which cause an increasing in the water/cement ratio and speeding up the cement hydration rate; hence, the cement pastes composites in substitution of both 2.5 and 5.0 mass \% NS possess high hydraulic characteristics. Hence, the setting time increases with increasing NS content. 
Fig. 5 Flowability, Initial and final setting times of NS blends

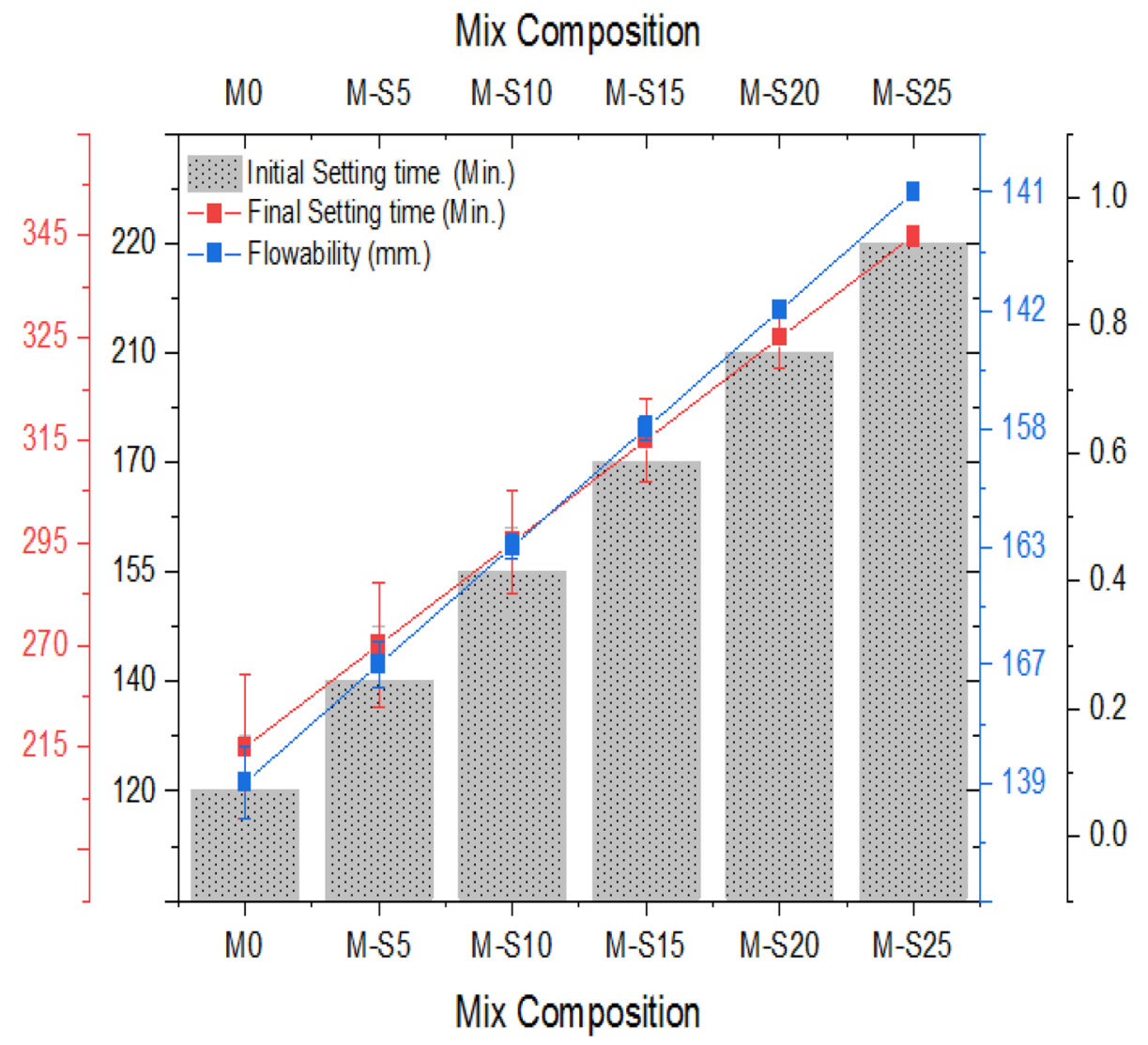

\section{Compressive strength (CS)}

Effectiveness of NS replacement on the CS of the composite pastes over 100 days hydration as a function of hydration ages represented in Fig. 6. The reported data showed an increasing in setting time results in increasing in the compressive mechanical strength for all hardened NS-white cement pastes, as the ongoing formalization of additional products of calcium aluminosilicate hydrates and calcium silicate hydrates (major source of solidification); both generated hydrates are completely deposited inside the open pores yields improvement in the competence of the specimen cement structure (Shaikh et al. 2014). Adding NS (5.0\%) improved the strength of the NS composite pastes. This is due to the NS behaving as a hydraulic filler which improves the matrix structure of the hardened cement blends, but also the pozzolanic effect of free silica ( $\mathrm{Si}$ ), amorphous particles, that causes the reaction of hydration with free lime and calcium. hydroxide to form the gels $\mathrm{CSH}, \mathrm{CAH}$ and $\mathrm{CASH}$ that forming the compacted and closed microstructure of the hardened white cement matrices (Sargam and Wang 2021). However, introducing NS is preferable to specific percentage (5\%), higher than this value may disturb the composite microstructure and affect the matrix. Moreover, ettringite might be preserved from converting to monosulfate; thus, it may lead to decrease of compressive mechanical strength effected by the internal structure stress as the abundant ettringite when the substitution of NS increased. The results also revealed that the compressive mechanical strength of the pastes of white cement composites combined with the NS is greater than that of the control sample. The NS increases the bulk density while decreasing the initial HP. In contrast, the compressive strength takes the following order: MS-5 > M0 > MS-10>MS-15>MS-20>MS-25 when the ratio of NS-blended white cement pastes decreased which is attributed to a reduction in the pozzolanic activities of the cement pastes composites (Shebl et al. 2009). The CS of the composite cement pastes comprising 95\% WC and 5\% NS is greater than the neat WC by $1,4,7$, and $12 \%$ for the specimens that cured at 3, 7,28, and 100 days, respectively. Another, important factor is the high alkaline content of WC, in both $\mathrm{Na}^{+}$and $\mathrm{K}^{+}$, leading to high sodium equivalent content of WC. These alkalis enhance the CS by around 7\%, forming $\mathrm{Na}^{+}-\mathrm{CSH}$ and $\mathrm{K}^{+}-\mathrm{CSH}$ (Falah et al. 2020; Sadrmomtazi et al. 2018).

\section{Bulk density (BD)}

Figure 7 depicts the bulk density of the WC composite in the NS hybrid, which have cured for 100 days. The bulk density grows as the hydration kinetics process of the cement phases progresses, in addition to the active nanosilica effect, 
Fig. 6 Compressive strength of WC- and NS-blended cement pastes
Curing time (days)

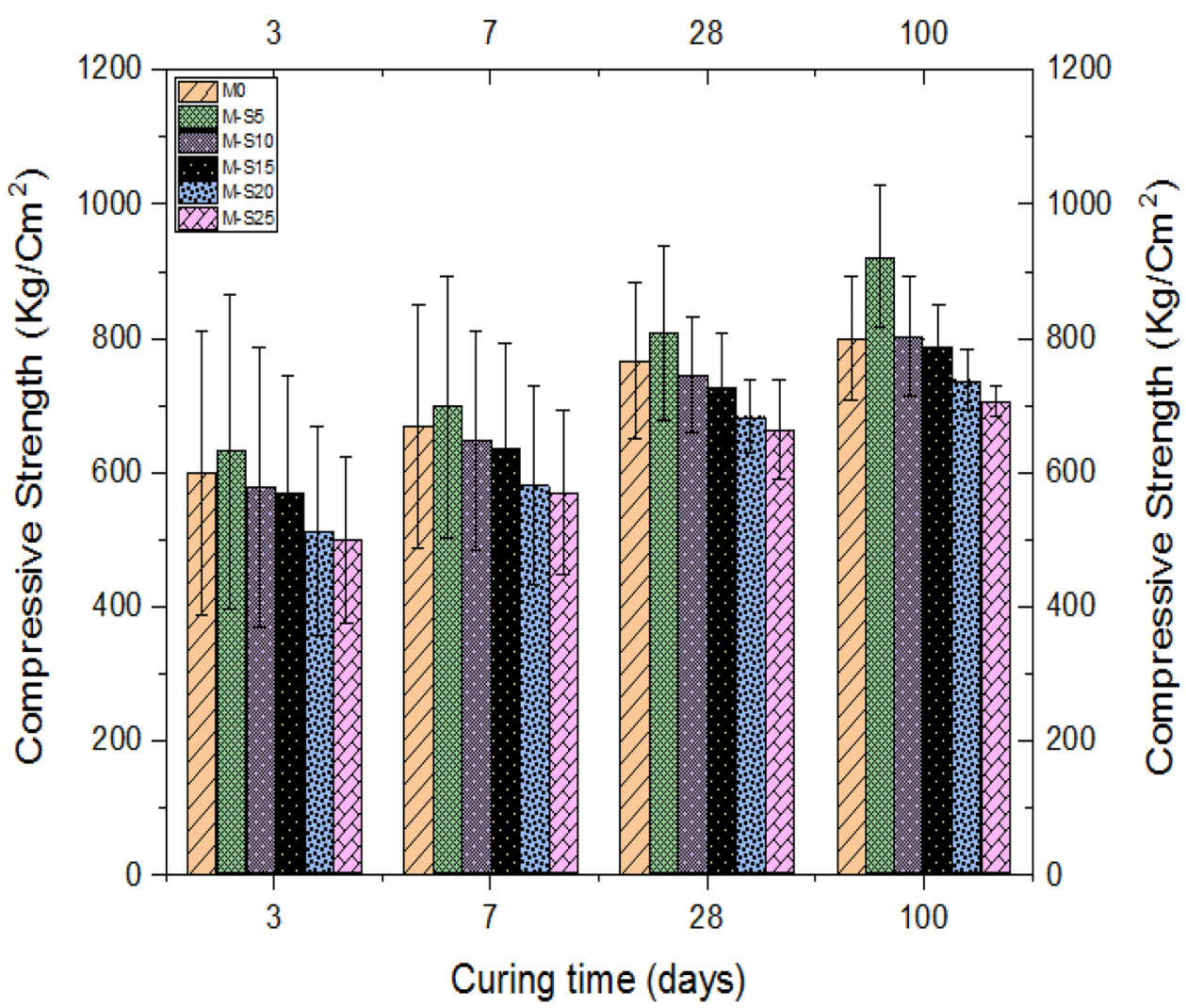

that is, the pozzolanic activity of the NS, to collect massive portion of hydrates able to increase the solidification of the composites. (Nunes et al. 2016). The mixtures with 5\% NS outperformed the control sample (M0) due to the reductions in the water-to-cement ratio, which enhances the CS characteristics, the conjugated $5 \mathrm{wt} . \% \mathrm{NS}$ has the greatest density value among the others. As the W/C drops, so does the $\mathrm{BD}$ rises. The results demonstrate that when the NS content increases, so does not the bulk density. The NS reacts with WC as the active nuclei can stimulate the hydraulic pozzolanic reaction of both silica oxide and alumina oxide, accordingly the hydration kinetics of anhydrous cement. NS influences the crystallization behavior of $\mathrm{CH}$ as well as the effectiveness of the pozzolanic kinetics reaction. The findings of the MS-15-25 mixes demonstrate a reduction in the results of CS, TP, and BD when the WC is replaced with $15-25 \%$ NS. The rise in bulk density of the WC blended with 5\% NS, on the other hand, shows greater values when compared to the findings of the other blends.

\section{Total porosity (TP)}

Figure 8 depicts the changes in the total porosity of NS composite pastes in the hybridization of NS mass percent. TP lowers as the number of hydrated products increases. The findings demonstrate the lowering TP results of the composite pastes in the NS hybridization, attributes to the additional quantities of calcium (aluminate and silicate) hydration products from the active action of the NS and CH's pozzolanic activity. The initial porosity with the volume of specimen pores diminishes, allowing the NS and lime to connect and produce $\mathrm{C}-\mathrm{A}-\mathrm{H}, \mathrm{C}-\mathrm{S}-\mathrm{H}$, and C-AS-H. The TP values of the cement composite pastes possess WC-NS; the MS-5 mix is decreased than the other cement composite pastes. The TP rises as the NS\% rises, since the MS-5 and M0 mixes having a lower TP value than the MS- 15 to MS-25 mixes due to the impact of the NS crystallinity shape.

\section{Hydration kinetics}

\section{Chemically combined water (Wt)}

Wt, of the WC-NS composite pastes over 100 curing days depicts in Fig. 9. The Wt \% provides information on class of phase hydration of cement composites pastes. The increase in Wt as the hydration time grows, owned to the highly increase in the developed products, which results in huge amounts of hydrates formation, resulting in improvement in the pore system filling inside the pastes. Furthermore, the addition of 5 percent NS in white cement composite

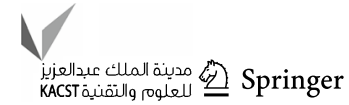


Fig. 7 Bulk density of WC- and NS-blended cement pastes

\section{Curing time (days)}

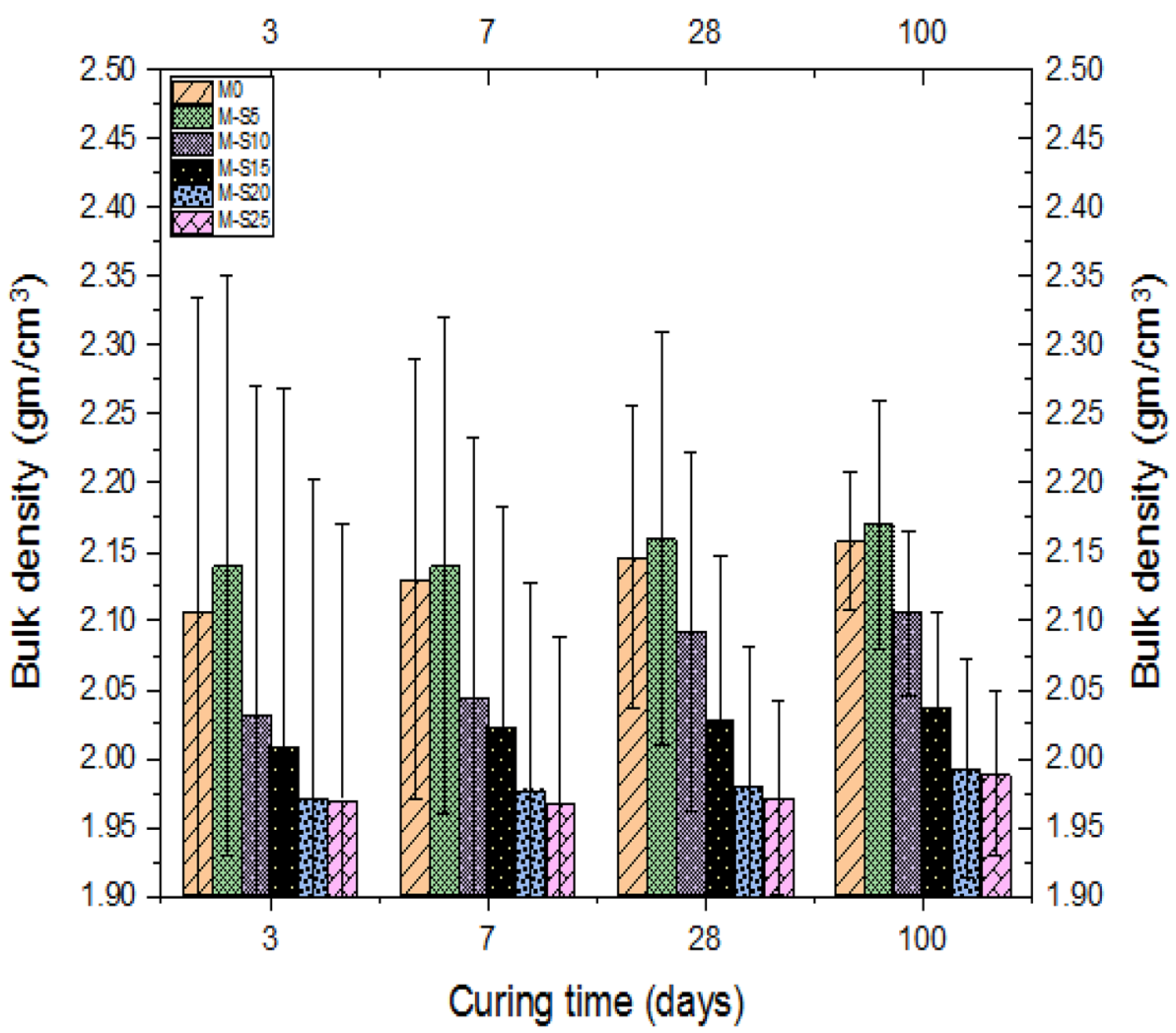

Fig. 8 Total porosity of WCand NS-blended cement pastes

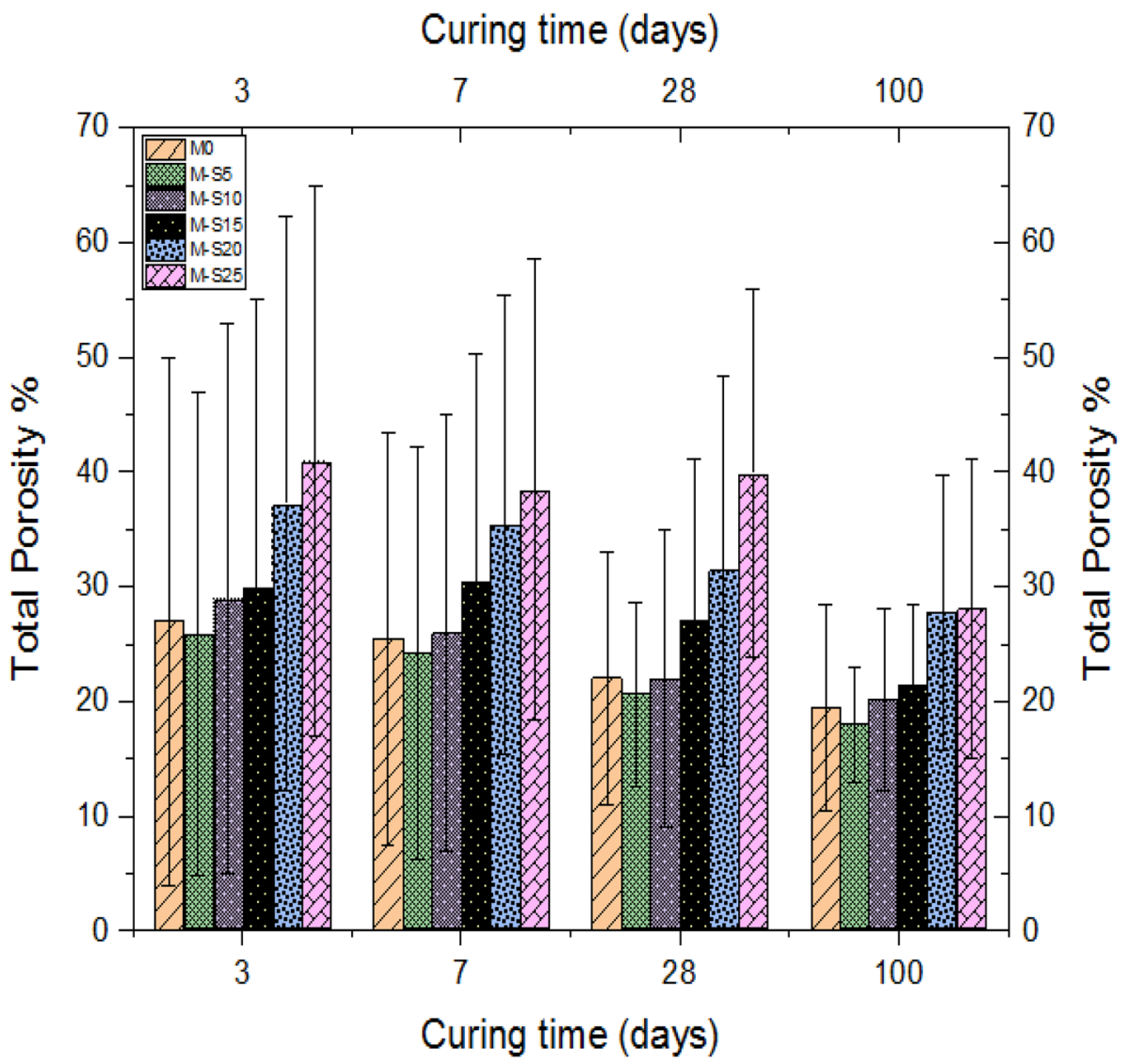


resulted in the greatest Wt values when compared to plain WC and other cement pastes incorporate by NS, i.e., MS$25<$ MS- $20<$ MS- $15<$ MS- $10<$ M0 $<$ MS-5. The 5\% NS mix is characteristic with very high specific surface area and unsaturated bonds, hence forming numerous active nucleation sites resulting in acceleration in the hydration process of the cement with special focus in early ages of hydration for specimens hydrated at $3(30 \%), 7$ (9\%), 28 (7\%) and 100 (3) days while the pozzolanic interaction with the $\mathrm{CH}$ and free lime content releasing along blends hydration to compose additional calcium (silicate and aluminate and potassium silicate) hydrates, sodium silicate hydrate and calcium aluminate products is sluggish at late hydration ages (Heikal et al. 2013). NS improves the formation of the CSH structure by filling the gaps about $90 \%$ of cement grains, resulting in a denser and stronger microstructure (Chen et al. 2016; Hou et al. 2012). The Wt decreases with \% NS at higher additions due to that silica has less cementations properties compared to cement clinker. The contents and water vapor rising from the others were approximated by reference to the final absolute mass of the mixtures at $1000{ }^{\circ} \mathrm{C}$, as shown for better illustration of the hydration process (Kawashima et al. 2013).

\section{Free lime content (FL)}

Figure 10 presents FL content of the NS cement composite cured up to 100 days. With curing age, results in the difference of free lime content up and down with NS content, where the free lime content decreases with increasing the curing time for replacement of NS by 5.0 and $10.0 \mathrm{wt} \%$, while increasing the NS above $10 \%$ resulting in increase in the free limel with increasing the curing ages; this might be attributed to continuous hydration reaction which liberates calcium hydrate during the hydration period. Addition of NS, the free lime content increases to 3 days in MS- 5 mix and subsequently decrease to 100 days in MS-10 mix. The NS supports the response rate of the cement-phase hydration, which is basically the release prop. of $\mathrm{CH}$ which is quicker more than the consumption rate as the pozzolanic role of NS, increasing the FL to 3 days (García-Taengua et al. 2015). The NS aids in the dispersal of the WC blends by pushing it to max compaction, reinforcement and low $\mathrm{TP}$, which relieves the contracting gap between the NS and the liberation of $\mathrm{CH}$, leads to fabricating of extra hydration products, $\mathrm{C}-\mathrm{S}-\mathrm{H}$, with enhancement the $\mathrm{CS}$. Mixtures with high content of NS (15-25\%) show a high percentage of
Fig. 9 Chemically combined water of WC- and NS-blended cement pastes

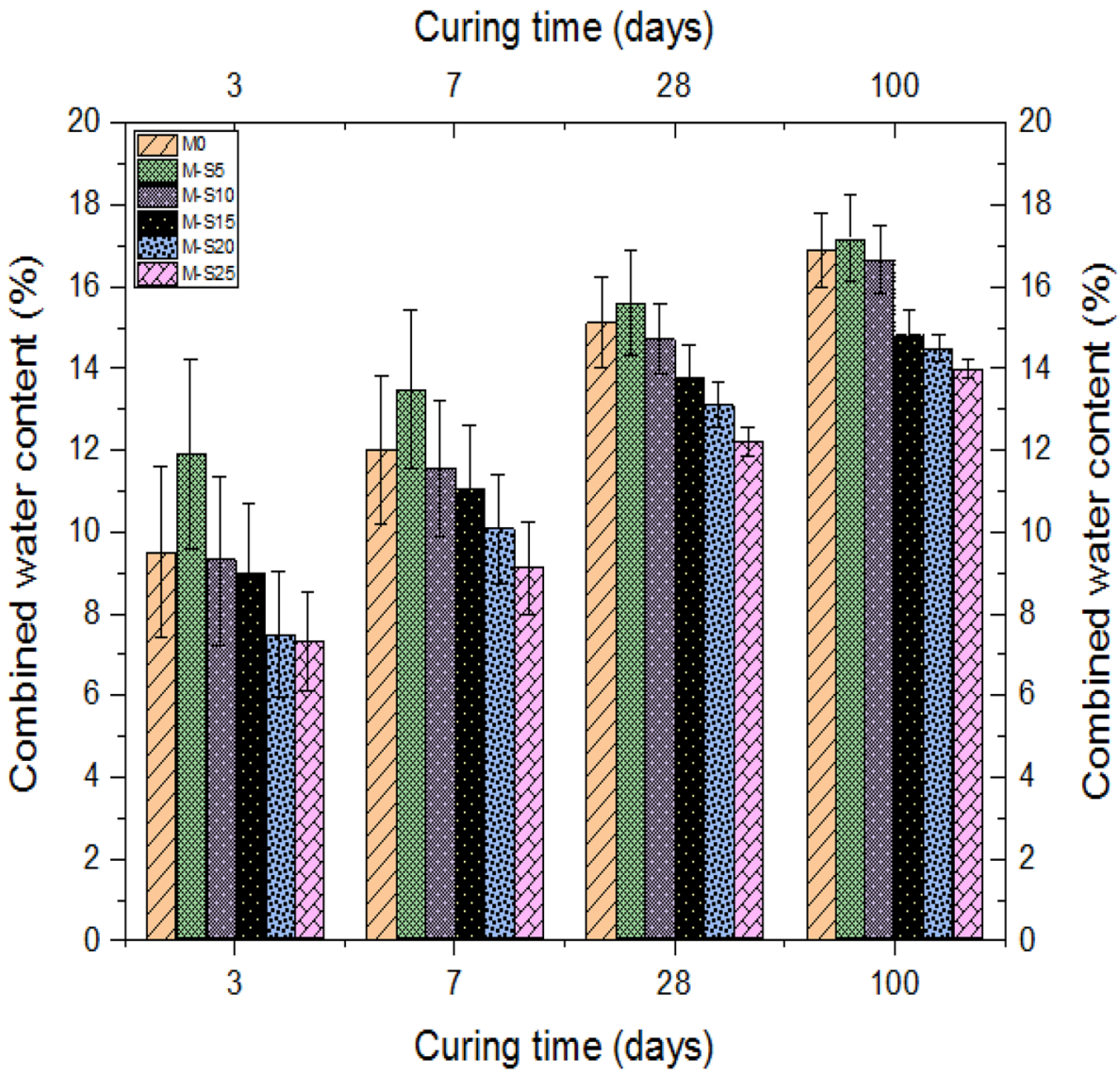


Fig. 10 Free lime content of WC- and NS-blended cement pastes

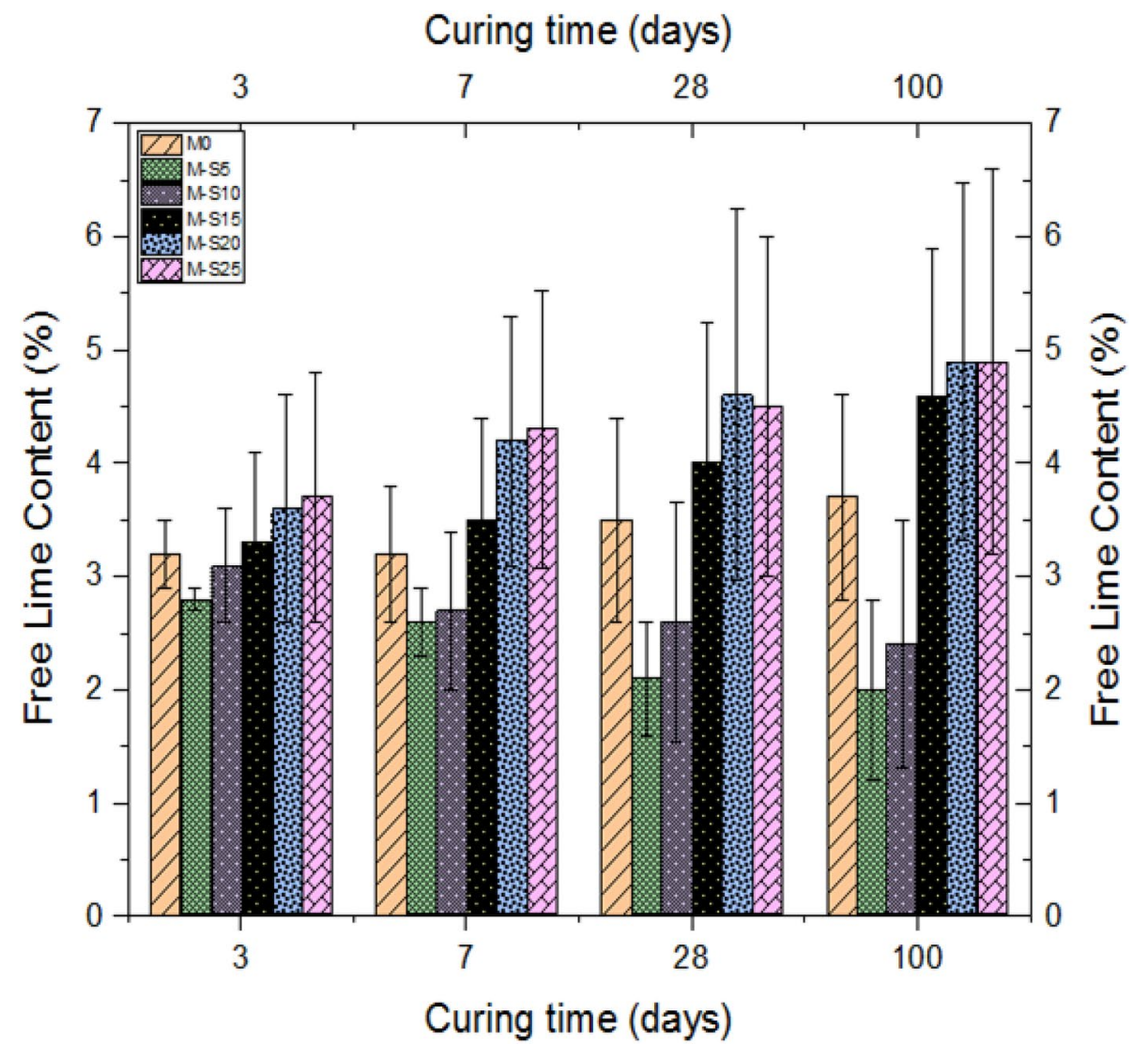

free lime due to silica which excites yielding of $\mathrm{C}-\mathrm{S}-\mathrm{H}$ up to a certain extent, then acts as inert fillers and because the nanosilica particles are large, the mixtures have high porosity and low bulk density.

\section{Microstructure features}

Figure 11 presents the SEM morphology and microstructure of the NS cement composite cured over 28 days. The photos displays the presence of high quantity of crystalline hydrates and layers of organized hexagonal texture from $\mathrm{CH}$ crystals combined to clear, tease, and well define porous structure. SEM depicts excess hydrates of fiber-gel CSH responsible for crosslinking a solid and closed cement structure with increased curing life over 100 days. The crystalline calcium silicate hydrate shows road-like particle and layers of arranged hexagonal texture of fiber-gel $\mathrm{CH}$ crystals are increased in M-S5 mix as it is the optimum percent value for the NS as active pozzolanic filler material. On the other hand, these crystalline and fibrous layers are decreased with high replacement of NS as it acts as complementary filler having slight hydraulic properties better than the inert fillers. The morphologically hardened specimen shows a squamous microstructure with a large number of pores filled with nanoparticles products that reflect on the mechanical strength of the specimen reducing the porosity which reflects the synergetic effect of NS. Replacement up to $25 \mathrm{wt}$. \% shows less dense matrix structure which might be attributed to less hydraulic properties of NS as higher replacement ratio. The role of the high alkaline content slightly enhances the arrangement of the microstructure due to its low reactivity after the sample solidifies.

\section{Synergistic features of blends}

\section{Compressive strength (CS)}

CS values of NS-blended cement composites pastes variation with fired temperatures $250,500,750$ to $1000{ }^{\circ} \mathrm{C}$ after 28 days of curing plotted in Fig. 12. CS raises along thermal treatment at $500{ }^{\circ} \mathrm{C}$ then severely reduces for all blends up to $1000{ }^{\circ} \mathrm{C}$. The highest compression values and the effective thermal resistance were recorded for M-S5, blends have been evaluated through thermally heat-treated temperature up to $1000{ }^{\circ} \mathrm{C}$, when it compared with neat WCs as the hydration kinetic process enhanced the un-hydrated cement clinker phases. It might be attributed to the self-autoclaving process of water steam pass through the open channels of cement paste eliminating the physically adhered water as explained at the schematic diagram in Fig. 13. WC samples replaced 

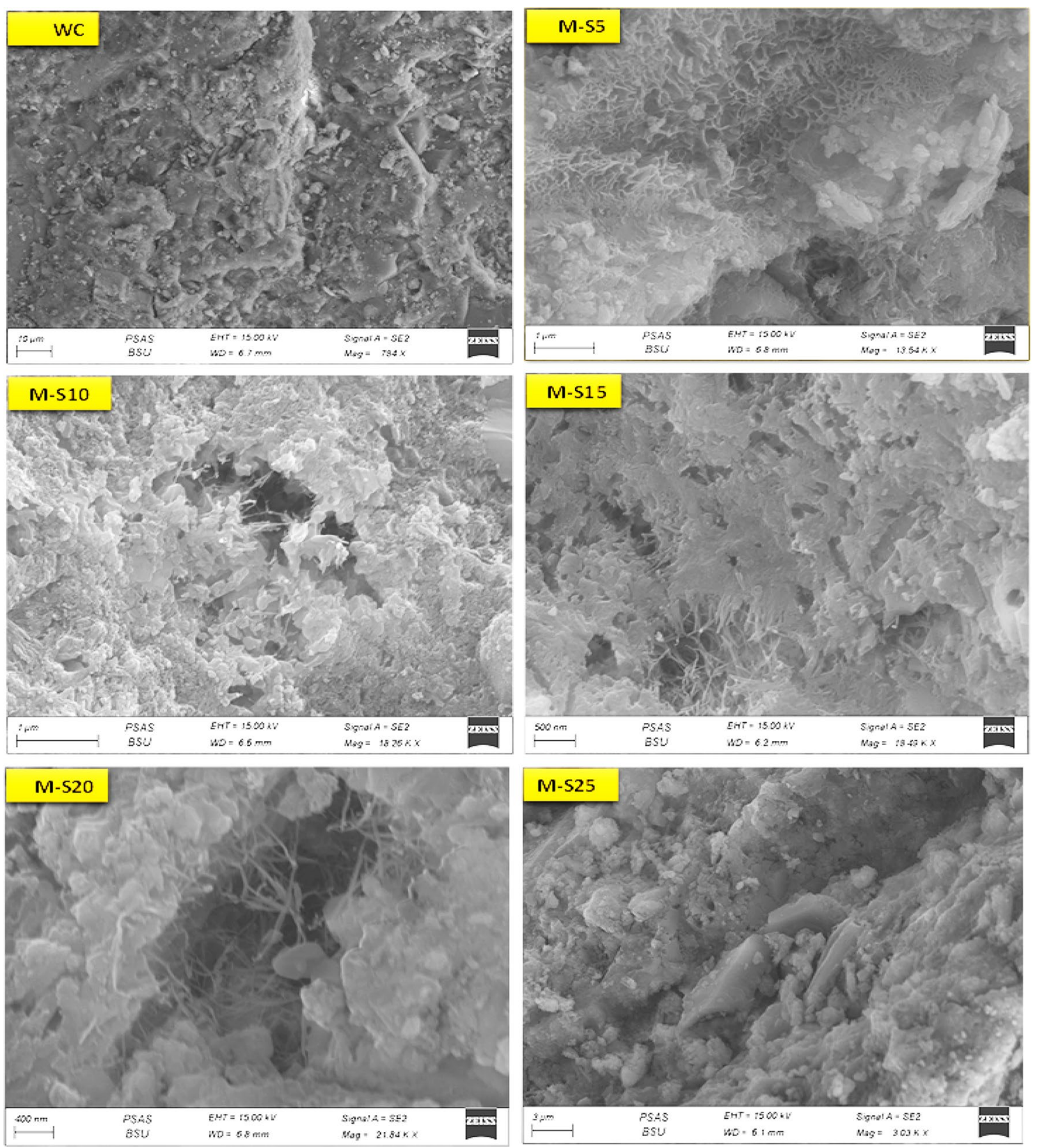

Fig. 11 Hydration products and microstructures of WC- and NS-blended cement pastes at 28 days of hydration

by $10,15,20$ and 25 by weight $\%$ of NS show almost similar syndrome, low fire resistance at certain temperatures levels which owned to increment of pastes TP due to the high coarsening of extra NS's addition of amorphous silicates and Gehlenite $\left(\mathrm{Ca}_{2} \mathrm{Al}_{2} \mathrm{SiO}_{7}\right)$ (Sargam and Wang 2021). At firing temperature up to $750{ }^{\circ} \mathrm{C}$ and $1000{ }^{\circ} \mathrm{C}$, extra phase fabrications tend to lose their $\mathrm{CS}$ values. On the other hand, M0 pastes reflect good fire resistance up to $1000{ }^{\circ} \mathrm{C}$ due to yielding extra hydrates.

\section{Microstructures features}

SEM morphology for the WC and NS blends fried $500{ }^{\circ} \mathrm{C}$ are displayed in Fig. 14. It is clear that the modified microstructure of the pastes demolished with high NS replacement due to the less reactivity of NS at higher replacement ratios (Deschner et al. 2013; Colston et al. 2000). SEM microstructure had performed for the M-S5 blend as it poses the better physico-mechanical features test results during the hydration 
Fig. 12 Compressive strength of WC and NS blends at varied thermal temperatures $(250,500$, 750 to $1000{ }^{\circ} \mathrm{C}$ ), at 28 days of hydration

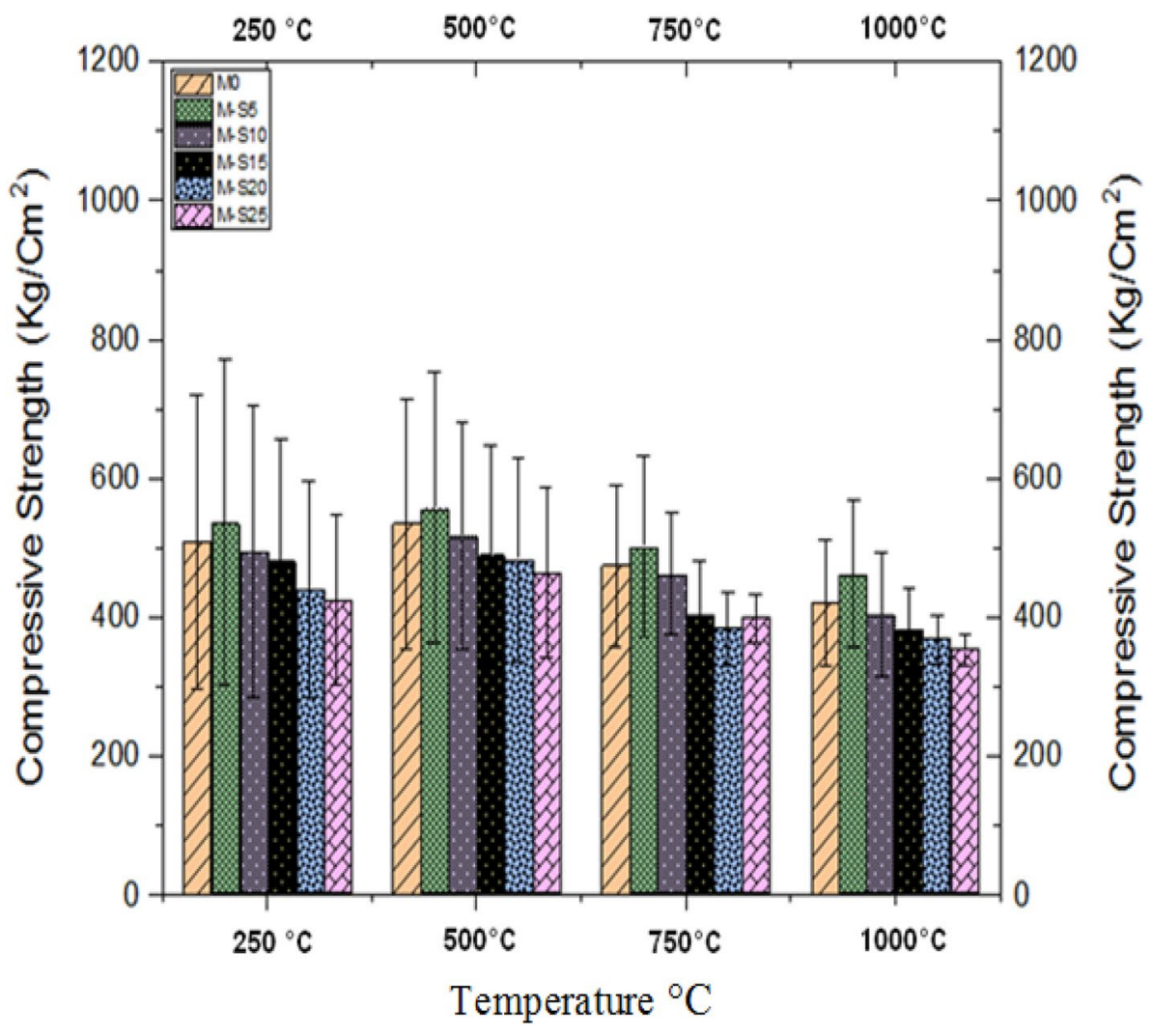

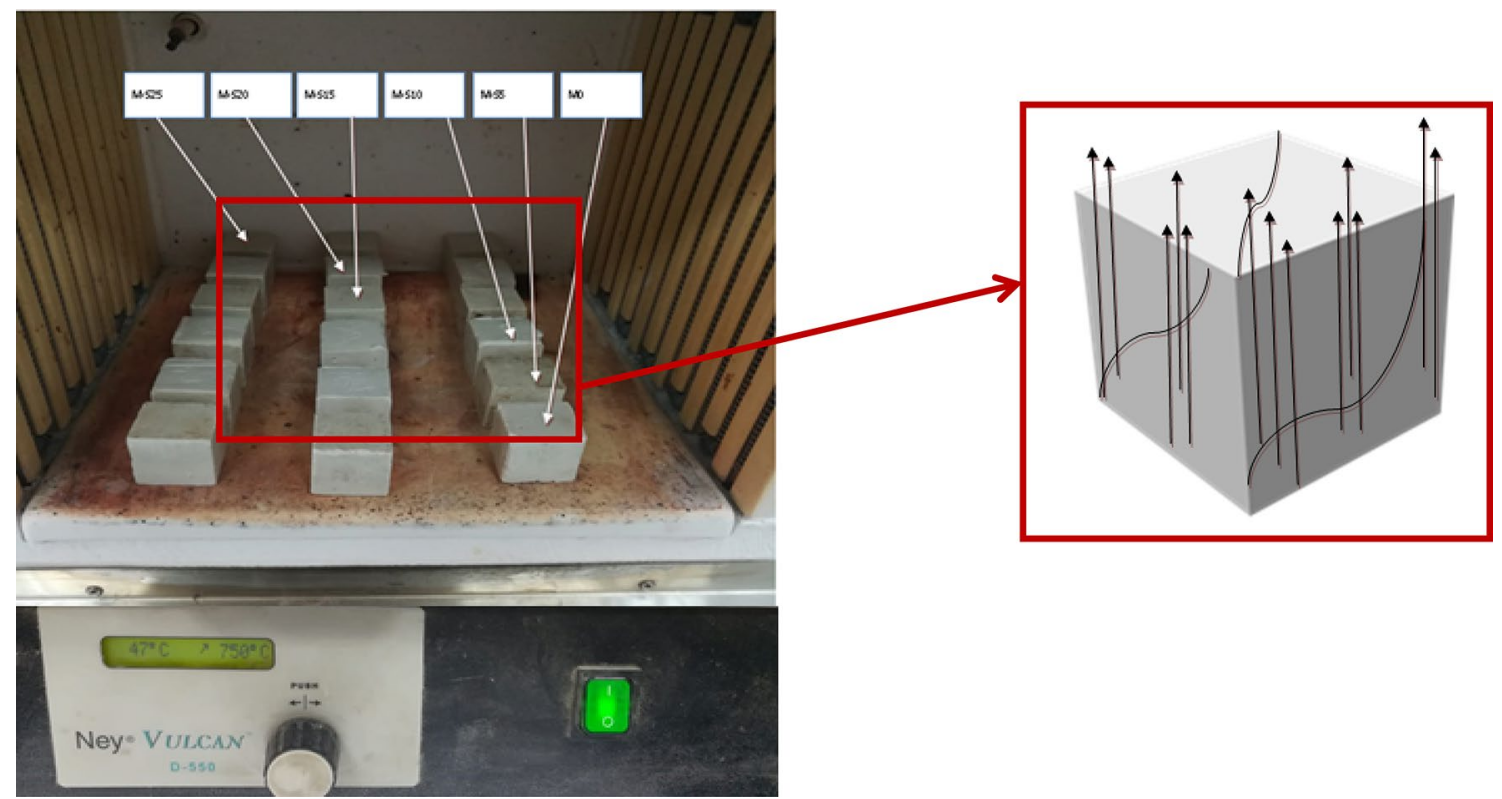

Fig. 13 Schematic diagram of the escape of water vapor leaving cracks in the microstructure of the specimen

periods. Figure 15 displays the microstructures features of M-S5 blend fired at varied thermal temperatures $(250,500$, 750 to $1000^{\circ} \mathrm{C}$ ). The matrix fibers, which reflect the calcium silicate hydrate content decreased simultaneously due to escaping of $\mathrm{CH}$ and $\mathrm{OH}^{-}$from the cube, leaving open pores leads to demolishing the skeleton structure, which negatively leads to not integrated and less fibrous $\mathrm{CH}$ and CSH crystals, embedded in the pores of the hydrated silicate products. Increasing thermal load on the specimens leads to demolishing of the reaming fibrous $\mathrm{CSH}$; but strange behavior 

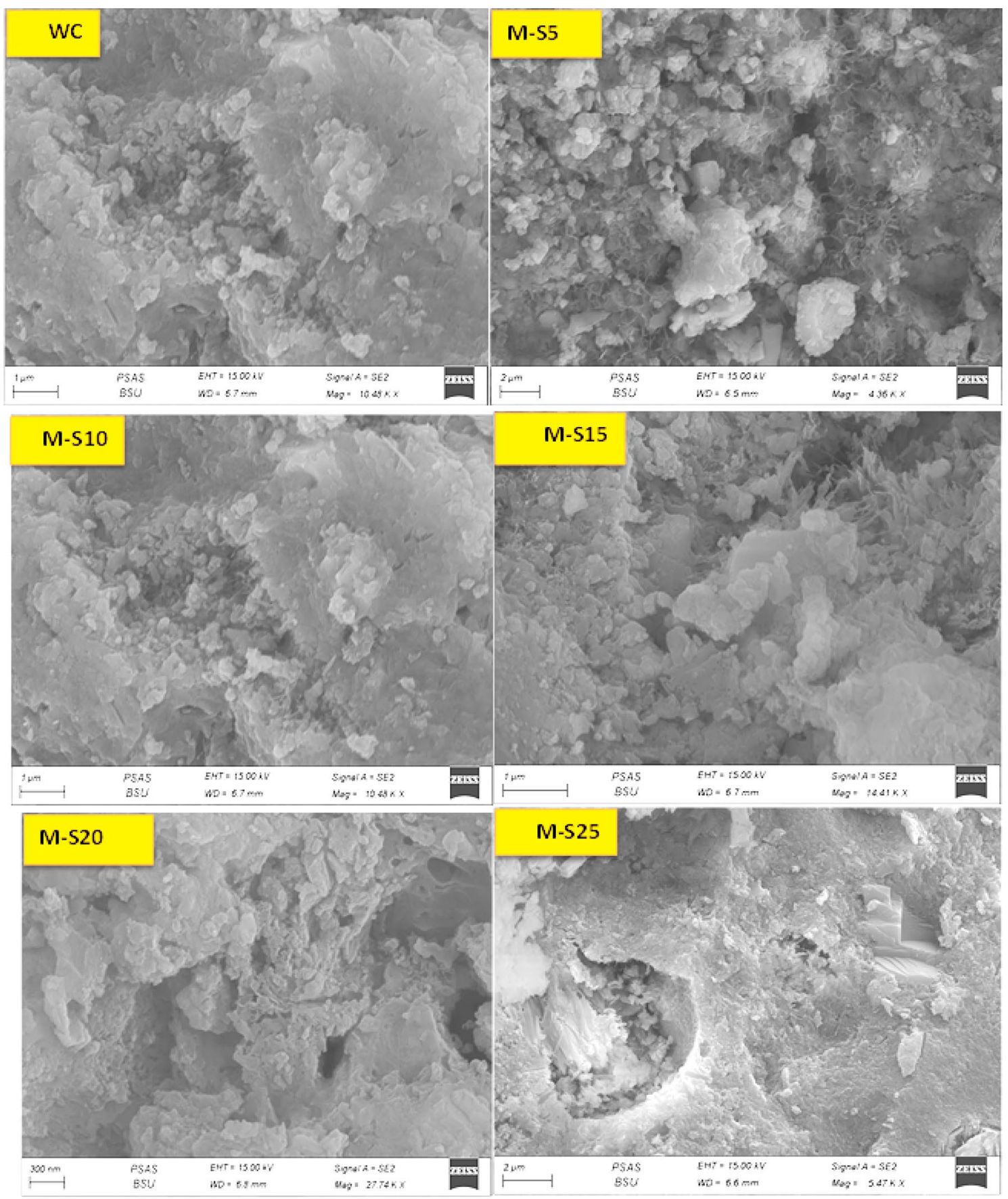

Fig. 14 Microstructures Features of WC and NS blends fired at $500{ }^{\circ} \mathrm{C}$ at 28 days of hydration

appears that the small quantity of these fibrous still exists at temperature up to $500{ }^{\circ} \mathrm{C}$ and $750{ }^{\circ} \mathrm{C}$ which might be attributed to high alkaline content in that white cement and promoting the strength as shown in Sect. 3.3. It is expected that alkali plays important role in blends behavior beside the pozzolanic activity of NS.

\section{Hydration products and XRD}

Figure 16 shows the XRD patterns and hydrated phases of WC, and nanosilica blends hydrated for 28 days and fired at varied thermal temperatures $\left(250,500,750\right.$ to $\left.1000{ }^{\circ} \mathrm{C}\right)$. Decreasing in the content of residual Portlandite in case of 

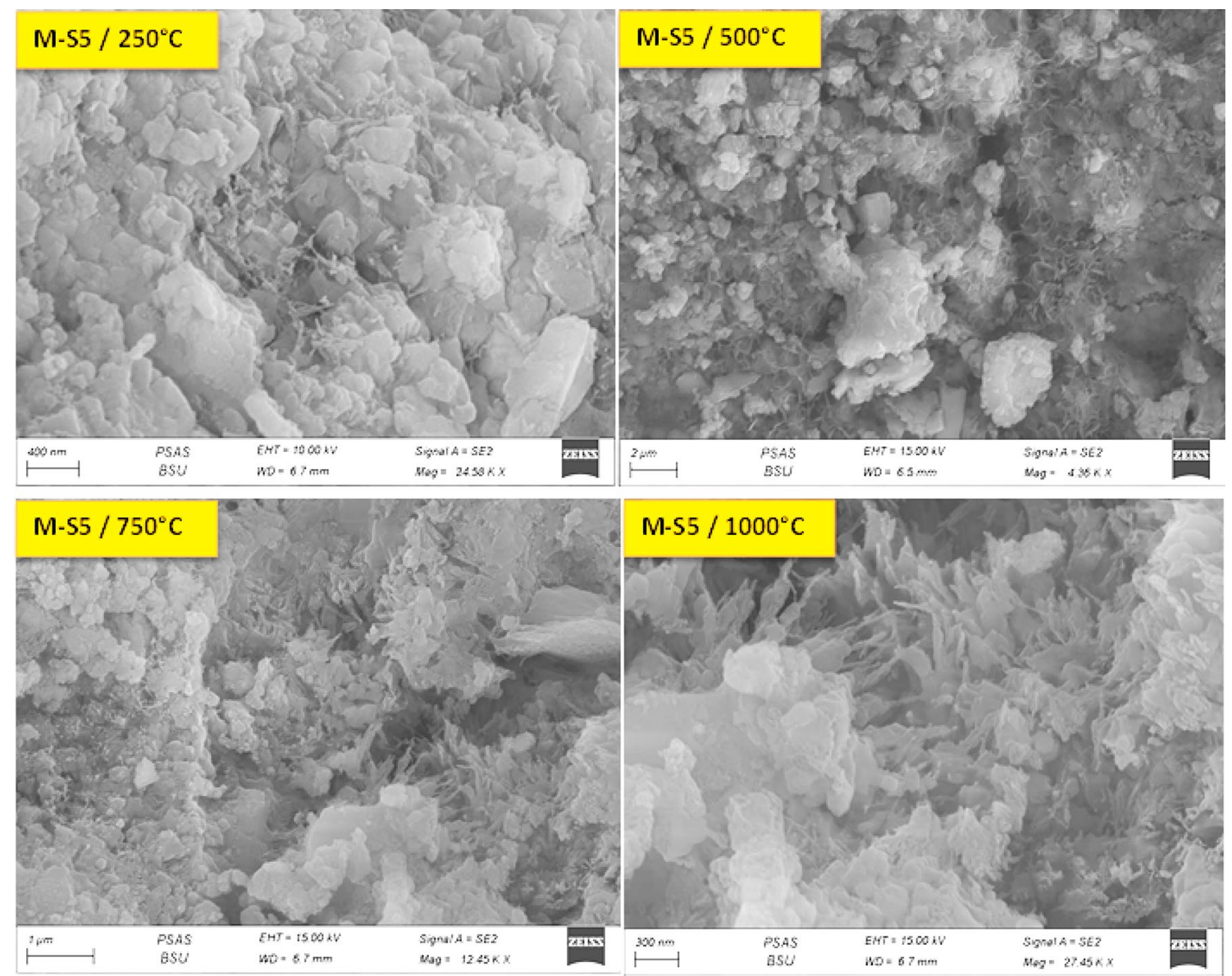

Fig. 15 Microstructures Features of M-S5 blend fired at varied thermal temperatures $\left(250,500,750\right.$ to $\left.1000{ }^{\circ} \mathrm{C}\right)$ at 28 days of hydration

NS-blended cement composites pastes attributed to decreasing WC content. The content of anhydrous calcium silicate minerals larnite $\beta-\mathrm{C} 2 \mathrm{~S}$, hatrurite $\mathrm{C} 3 \mathrm{~S}, \mathrm{~W}, \mathrm{C}^{-}, \mathrm{CSH}$, and ettringite decreases in case of NS blends pastes as the pozzolanic action of nanosilica by reacting with portlandite (liberates from hydration kinetics of cement) forming extra hydrates (Esteves 2011; El-Roudi et al. 2015). Quartz peaks were clearly detected in all blends increasing the strength and resistivity to fire, but with raising the fire rate, the quartz strength and resistivity to fire decrease as losing of $\mathrm{CSH}, \mathrm{W}$ and $\mathrm{C}^{-}$contents.

\section{Conclusion}

The effect of NS on hydration kinetics of highly alkaline white cement composites was evaluated. The results demonstrate that partially replacing white cement with nano-silica filler leads to decrease in the whiteness of dry blends, accordingly retarding the setting times and TP of blends. Nevertheless, it increases CS, combined water content and BD of WC-NS pastes due to the pozzolanic effect of nano-silica that replaces clinker acting as active nuclei and increases the amount of $\mathrm{C}-\mathrm{S}-\mathrm{H}$ hydrate products. Portlandite was detected in nano-silica blends hydrated for 7 days indicating the pozzolanic effect of nanosilica at early ages of hydration, whereas C3S and C2S were detected in NS blends hydrated up to 28 days indicating that NS effect accelerates the rate of hydration of $\mathrm{C} 3 \mathrm{~S}$ at later ages of hydration. The experimental outcomes also show that, nano-silica alters the microstructure of hardened cement pastes. The morphology of $\mathrm{C} 3 \mathrm{~S}$ and $\mathrm{C} 2 \mathrm{~S}$ originally changes with progress of hydration. Therefore, this study proposes a maximum content of nano-silica nanoparticles that do not exceed 5\% as a partial substitution of white cement to reach optimum cement blends performances. 


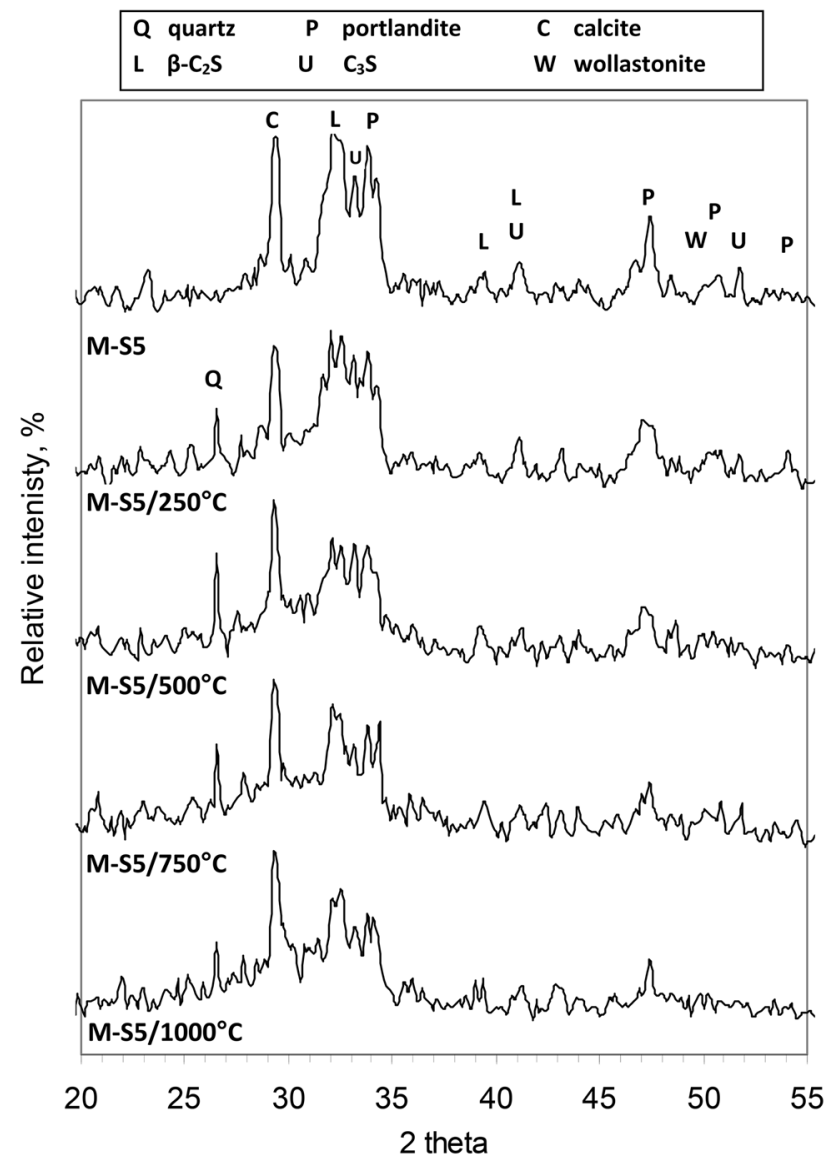

Fig. 16 Hydration products of M-S5 blend hydrated for 28 days and fired at varied thermal temperatures $\left(250,500,750\right.$ to $\left.1000{ }^{\circ} \mathrm{C}\right)$

Funding Open access funding provided by The Science, Technology \& Innovation Funding Authority (STDF) in cooperation with The Egyptian Knowledge Bank (EKB).

\section{Declarations}

Conflict of interest There is no conflict of interest.

Open Access This article is licensed under a Creative Commons Attribution 4.0 International License, which permits use, sharing, adaptation, distribution and reproduction in any medium or format, as long as you give appropriate credit to the original author(s) and the source, provide a link to the Creative Commons licence, and indicate if changes were made. The images or other third party material in this article are included in the article's Creative Commons licence, unless indicated otherwise in a credit line to the material. If material is not included in the article's Creative Commons licence and your intended use is not permitted by statutory regulation or exceeds the permitted use, you will need to obtain permission directly from the copyright holder. To view a copy of this licence, visit http://creativecommons.org/licenses/by/4.0/.

\section{References}

Abbas R, Shehata N, Mohamed EA, Salah H, Abdelzaher M (2021) Environmental safe disposal of cement kiln dust for the production of geopolymers. Egypt J Chem 64(12):7429-7437

Abdelzaher MA (2021) Experiential investigation on the effect of heavy fuel oil substitution by high sulfur petcoke on the physicomechanical features and microstructure of white cement composites. Eng Res Express 3(1):015028

Abdelzaher MA, Hamouda AS, Ismail IM, El-Sheikh MA (2018) Nano titania reinforced limestone cement: physico-mechanical investgation. In: Key Engineering Materials, vol. 786, pp. 248-257. Trans Tech Publications Ltd.

Abdullah A, Alhozaimy A (2013) Effect of various activation methods on the reactivity of ground dune sand as partial cement replacement. In: 2013 IEEE business engineering and industrial applications colloquium (BEIAC) (pp. 290-295). IEEE

Alhozaimy A, Jaafar MS, Al-Negheimish A, Abdullah A, Taufiq-Yap YH, Noorzaei J, Alawad OA (2012) Properties of high strength concrete using white and dune sands under normal and autoclaved curing. Constr Build Mater 27(1):218-222

Alhozaimy A, Fares G, Al-Negheimish A, Jaafar MS (2013) The autoclaved concrete industry: an easy-to-follow method for optimization and testing. Constr Build Mater 49:184-193

Ali MS, Khan IA, Hossain MI (2008) Chemical analysis of ordinary Portland cement of Bangladesh. Chem Eng Res Bull 12:7-10

Al-Jabri K, Baawain M, Taha R, Al-Kamyani ZS, Al-Shamsi K, Ishtieh A (2013) Potential use of FCC spent catalyst as partial replacement of cement or sand in cement mortars. Constr Build Mater 39:77-81

American Society for Testing and Materials (1999) ASTM C 403: standard test method for time of setting of concrete mixture by penetration resistance. In: Annual book of ASTM standards

Antwi-Afari P, Ng ST, Hossain MU (2021) A review of the circularity gap in the construction industry through scientometric analysis. J Clean Prod. https://doi.org/10.1016/j.jclepro.2021.126870

ASTM C150-07 (2007) Standard specifications for portland cement. American Society for Testing and Materials, West Conshohocken

ASTM C191 (2013) Standard test methods for time of setting of hydraulic cement by vicate needle

ASTM C109/C109M (2016) Standard test method for compressive strength of hydraulic cement mortars

Avet F, Boehm-Courjault E, Scrivener K (2019) Investigation of CASH composition, morphology and density in Limestone Calcined Clay Cement (LC3). Cem Concr Res 115:70-79

Balboul BA, Abdelzaher M, Hamouda AS, Zaki AH (2019) Nano titania combined with micro silica reinforced limestone cement: physico-mechanical investigation. Egypt J Chem 62(6):1105-1115

Cao Y, Zavaterri P, Youngblood J, Moon R, Weiss J (2015) The influence of cellulose nanocrystal additions on the performance of cement paste. Cem Concr Compos 56:73-83

Chen Y, Deng YF, Li MQ (2016) Influence of nano- $\mathrm{SiO}_{2}$ on the consistency, setting time, early-age strength, and shrinkage of composite cement pastes. Adv Mater Sci Eng. https://doi.org/10.1155/ 2016/5283706

Colston SL, O'connor D, Barnes P, Mayes EL, Mann S, Freimuth H, Ehrfeld W (2000) Functional micro-concrete: the incorporation of zeolites and inorganic nano-particles into cement micro-structures. J Mater Sci Lett 19(12):1085-1088 
Damidot D, Lothenbach B, Herfort D, Glasser FP (2011) Thermodynamics and cement science. Cem Concr Res 41(7):679-695

Deschner F, Lothenbach B, Winnefeld F, Neubauer J (2013) Effect of temperature on the hydration of Portland cement blended with siliceous fly ash. Cem Concr Res 52:169-181

El-Kattan IM, Abdelzaher MA, Farghali AA (2020) Positive impact of ultra fine-ceramic waste on the physico-mechanical features and microstructure of white cement pastes composites. J Market Res 9(4):9395-9402

Elkhouly HI, Abdelzaher MA, El-Kattan IM (2021) Experimental and modeling investigation of physicomechanical properties and firing resistivity of cement pastes incorporation of micro-date seed waste. Iran J Sci Technol Trans Civ Eng. https://doi.org/10.1007/ s40996-021-00760-2

El-Roudi AM, Balboul BA, Abdelzaher M (2015) Influence of limestone on physico-chemical properties of white portland s pastes. Int J 3(6):210-221

Esteves LP (2011) On the hydration of water-entrained cement-silica systems: Combined SEM, XRD and thermal analysis in cement pastes. Thermochim Acta 518(1-2):27-35

Falah M, Ohenoja K, Obenaus-Emler R, Kinnunen P, Illikainen M (2020) Improvement of mechanical strength of alkali-activated materials using micro low-alumina mine tailings. Construct Build Mater 248:118659

García-Taengua E, Sonebi M, Hossain KMA, Lachemi M, Khatib $\mathrm{J}$ (2015) Effects of the addition of nanosilica on the rheology, hydration and development of the compressive strength of cement mortars. Compos B Eng 81:120-129

Guettala S, Mezghiche B (2011) Compressive strength and hydration with age of cement pastes containing dune sand powder. Constr Build Mater 25(3):1263-1269

Heikal M, Abd El Aleem S, Morsi WM (2013) Characteristics of blended cements containing nano-silica. HBRC J 9(3):243-255

Hou P, Wang K, Qian J, Kawashima S, Kong D, Shah SP (2012) Effects of colloidal nano $\mathrm{SiO}_{2}$ on fly ash hydration. Cem Concr Compos 34(10):1095-1103

Hou P, Kawashima S, Kong D, Corr DJ, Qian J, Shah SP (2013) Modification effects of colloidal nanoSiO 2 on cement hydration and its gel property. Compos B Eng 45(1):440-448

Hou P, Muzenda TR, Li Q, Chen H, Kawashima S, Sui T, Cheng X (2021) Mechanisms dominating thixotropy in limestone calcined clay cement (LC3). Cem Concr Res 140:106316

Janotka I, Puertas F, Palacios M, Kuliffayová M, Varga C (2010) Metakaolin sand-blended-cement pastes: rheology, hydration process and mechanical properties. Constr Build Mater 24(5):791-802

Juenger MC, Snellings R, Bernal SA (2019) Supplementary cementitious materials: new sources, characterization, and performance insights. Cem Concr Res 122:257-273

Kawashima S, Hou P, Corr DJ, Shah SP (2013) Modification of cement-based materials with nanoparticles. Cem Concr Compos $36: 8-15$

Kurda R, de Brito J, Silvestre JD (2019) Water absorption and electrical resistivity of concrete with recycled concrete aggregates and fly ash. Cem Concr Compos 95:169-182

Lin KL, Hwang CL, Shie JL, Chang YM, Cheng A (2014) Hydration characteristics of waste catalysts used as pozzolanic materials. Environ Prog Sustain Energy 33(2):353-358

Nguyen QD, Khan M, Castel A, Kim T (2020a) Mitigation of alkalisilica reaction in limestone calcined clay cement-based mortar. In: Calcined Clays for Sustainable Concrete (pp. 665-672). Springer, Singapore.
Nguyen QD, Kim T, Castel A (2020b) Mitigation of alkali-silica reaction by limestone calcined clay cement (LC3). Cem Conc Res 137:106176

NORM, DIN (1992). 5033-2

Nunes C, Slížková Z, Stefanidou M, Němeček J (2016) Microstructure of lime and lime-pozzolana pastes with nanosilica. Cem Concr Res 83:152-163

Pillai RG, Gettu R, Santhanam M, Rengaraju S, Dhandapani Y, Rathnarajan S, Basavaraj AS (2019) Service life and life cycle assessment of reinforced concrete systems with limestone calcined clay cement (LC3). Cem Concr Res 118:111-119

Sadrmomtazi A, Tahmouresi B, Saradar A (2018) Effects of silica fume on mechanical strength and microstructure of basalt fiber reinforced cementitious composites (BFRCC). Constr Build Mater 162:321-333

Sargam Y, Wang K (2021) Influence of dispersants and dispersion on properties of nanosilica modified cement-based materials. Cem Concr Compos 118:103969

Shaikh FUA, Supit SWM, Sarker PK (2014) A study on the effect of nano silica on compressive strength of high volume fly ash mortars and concretes. Mater Des 60:433-442

Sharma M, Bishnoi S, Martirena F, Scrivener K (2021) Limestone calcined clay cement and concrete: a state-of-the-art review. Cem Concr Res 149:106564

Shebl S, Allie L, Morsy M, Aglan HA (2009) Mechanical behavior of activated nano silicate filled cement binders. J Mater Sci 44(6):1600-1606

Shi Z, Shi C, Wan S, Zhang Z (2018) Effects of alkali dosage and silicate modulus on alkali-silica reaction in alkali-activated slag mortars. Cem Concr Res 111:104-115

Tantawy MA, El-Roudi AM, Abdalla EM, Abdelzaher MA (2012) Evaluation of the pozzolanic activity of sewage sludge ash. Int Schol Res Not 2012.

Tantawy MA, El-Roudi AM, Abdalla EM, Abdelzaher MA (2013) Fire resistance of sewage sludge ash blended cement pastes. J Eng. https://doi.org/10.1155/2013/361582

Tayeh BA, Al Saffar DM, Alyousef R (2020) The utilization of recycled aggregate in high performance concrete: a review. J Market Res 9(4):8469-8481

Thomas M (2011) The effect of supplementary cementing materials on alkali-silica reaction: a review. Cem Concr Res 41(12):1224-1231

Velázquez S, Monzó J, Borrachero MV, Soriano L, Payá J (2016) Evaluation of the pozzolanic activity of spent FCC catalyst/fly ash mixtures in Portland cement pastes. Thermochim Acta 632:29-36

Wilińska I, Pacewska B (2014) Calorimetric and thermal analysis studies on the influence of waste aluminosilicate catalyst on the hydration of fly ash-cement paste. J Therm Anal Calorim 116(2):689-697

Zhang G, Song J, Yang J, Liu X (2006) Performance of mortar and concrete made with a fine aggregate of desert sand. Build Environ 41(11):1478-1481

Zhang MH, Islam J, Peethamparan S (2012) Use of nano-silica to increase early strength and reduce setting time of concretes with high volumes of slag. Cem Concr Compos 34(5):650-662

Publisher's Note Springer Nature remains neutral with regard to jurisdictional claims in published maps and institutional affiliations. 